\title{
Deep breathing and awake apnoea in a patient who had recurrent hypoxaemia and hypercapnia without sleep apnoea
}

\author{
K. Chin*, Y. Oku*, K. Nishimura**, M. Ohi*
}

Deep breathing and awake apnoea in a patient who had recurrent hypoxaemia and hypercapnia without sleep apnoea. K. Chin, Y. Oku, K. Nishimura, M. Ohi. (OERS Journals Ltd 1998.

ABSTRACT: A 21 yr old with deep breathing and awake apnoea, who had recurrent hypoxaemia and hypercapnia without sleep apnoea, was presented. Although the organic abnormality responsible for the breathing disturbance was not found, administration of acetazolamide facilitated several breaths between sighs, and the patient's hypoxaemia with hypercapnia improved.

Some patients who have abnormalities in the cortical control of breathing that cannot be detected by present methods of examination may experience some improvement in breathing with the administration of chemical stimulants such as acetazolamide. Eur Respir J 1998; 12: 739-741.
*Dept of Clinical Physiology and **Dept of Respiratory Medicine and Environmental Respiratory Disease, Chest Disease Research Institute, Kyoto University, Kyoto, Japan.

Correspondence: K. Chin, Dept of Clinical Physiology, Chest Disease Research Institute, Kyoto University, Shogoin-kawaharacho 53, Sakyo-Ku, Kyoto 606-8397, Japan. Fax: 81757513854

Keywords: Acetazolamide, awake apnoea, primary alveolar hypoventilation

Received: October 271997

Accepted after revision April 131998
Primary alveolar hypoventilation is characterized by alveolar hypoventilation in the absence of mechanical hypoventilation [1]. In most patients, hypoventilation is more severe during sleep, and apneic periods are common [2-4]. Some patients with primary alveolar hypoventilation have no demonstrable ventilatory response to hypoxia during wakefulness [2, 3]. In general, a patient who shows hypoxaemia with hypercapnia during wakefulness is prone to show a further deterioration in blood gases during sleep. We report on a patient who showed central apnoeas with sighs during wakefulness with hypoxaemia and hypercapnia. He had no abnormal breathing during sleep and had normal lung function and normal ventilatory responses to hypoxia and hypercapnia. Administration of a respiratory stimulant (acetazolamide) eliminated apnoeas between sighs, and the patient's hypoxaemia and hypercapnia improved.

\section{Case report}

A 21 yr old male with dyspnoea was admitted to the Hospital of Chest Disease Research Institute, Kyoto University because of recurrent hypoxaemia with hypercapnia over a 3-month period (arterial oxygen tension $\left(\mathrm{Pa}, \mathrm{O}_{2}\right) 9.2$ (1.6 sD) kPa, 95\% confidence intervals (CI) (7.9-10.5); arterial carbon dioxide tension $\left(\mathrm{Pa}_{\mathrm{a}} \mathrm{CO}_{2}\right) 6.3(0.3) \mathrm{kPa}(6.0-6.5)$; pH 7.387 (0.014) (7.376-7.399); n=8) (fig. 1). The patient was $165 \mathrm{~cm}$ tall, and his weight was $60 \mathrm{~kg}$. The patient sighed irregularly at $10-50 \mathrm{~s}$ intervals. Medical staff, including physicians, psychoneurologists and nurses, did not find any evidence of a psychiatric problem. The patient had not been exposed to any known toxins, and had not taken any drugs, other than smoking 20 cigarettes.day ${ }^{-1}$. The patient's heart size and functional assessment by echocardiography were normal. Despite hypercapnia, he was suspected to have a pulmonary embolism, as evidenced by recurrent hypoxaemia. The patient's pulmonary scintigram, however, was normal, and his pulmonary function was also normal (\% vital capacity, 127\%; forced expiratory volume in one second (FEV1)/forced vital capacity (FVC) ratio, $82 \%$; \% diffusing capacity, $112 \%$ ). He was suspected to have a central nervous system abnormality, possibly multiple sclerosis, because his symptoms and arterial blood gas data fluctuated considerably (fig. 1). Magnetic

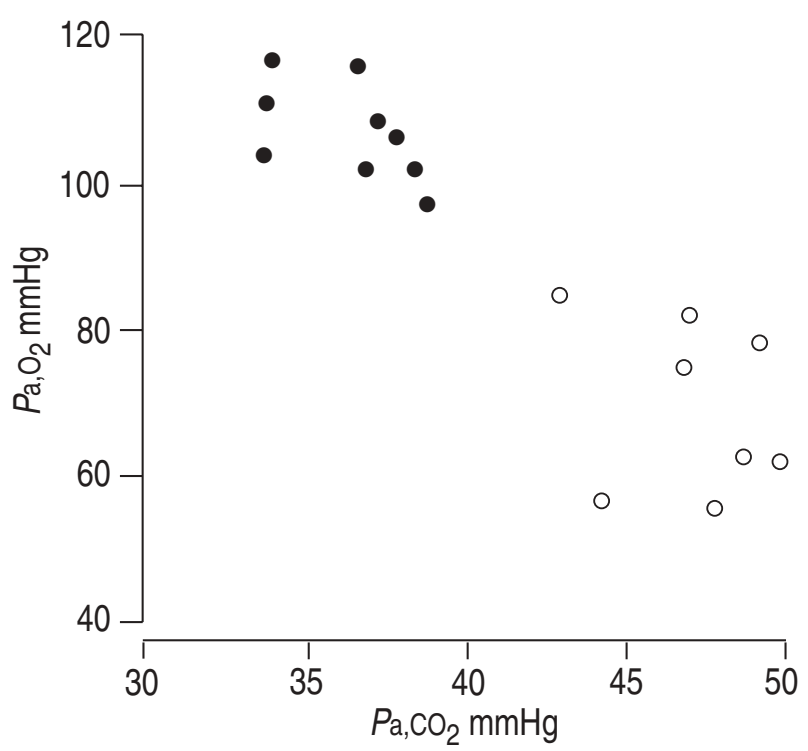

Fig. 1. - Arterial blood gas data before $(\bigcirc)$ and after $(\bullet)$ acetazolamide treatment. Analyses of arterial blood gases were executed eight times during the three-month period before treatment and nine times during a follow-up period of more than $1 \mathrm{yr}$ after treatment. $P \mathrm{a}, \mathrm{O}_{2}$ : arterial oxygen tension; $P$ a, $\mathrm{CO}_{2}$ : arterial carbon dioxide tension. $(1 \mathrm{mmHg}=0.133 \mathrm{kPa}$. $)$ 
resonance imaging (MRI), however, revealed the patient's brain to be normal. Moreover, the analysis of cerebrospinal fluid (CSF) was normal without any oligoclonal bands, and the myelin basic protein levels in CSF were also within the normal range. His hypoxic and hypercapnic ventilatory responses were both within normal ranges (hypoxic, $-0.22 \mathrm{~L} \cdot \mathrm{min}^{-1} \% \%^{-1}$; hypercapnic, $2.1 \mathrm{~L} \cdot \mathrm{min}^{-1}$. $\mathrm{mmHg}^{-1}$ in our laboratory [5]).

His breathing patterns were monitored using conventional polysomnographic methods with electroencephalography (EEG), electromyography (EMG) of the chin, electro-oculography (EOG), inductance plethysmography, pulse oximetry, and thermistors. All parameters were recorded in the data recorder (Sony 621A; Sony, Tokyo, Japan) and computer system (Sleep Analyzing Computer; Oxford Instruments Oxford, UK). While awake, he showed deep breathing in combination with central apnoea, which was perceived as a series of sighs (fig. 2a). At the end stage of apnoea while awake, the oxygen desaturation was exhibited in accordance with the duration of apnoea. When the apnoea duration was $>15 \mathrm{~s}$, change in arterial oxygen saturation $\left(\hat{y} S_{\mathrm{a}}, \mathrm{O}_{2}\right)=0.11 \times($ apnoea duration $)+3.65$; $\mathrm{r}=0.59, \mathrm{p}<0.02, \mathrm{n}=15$. During napping, his breathing was regular without apnoea or oxygen desaturation (fig. 2b). Oximeter monitoring during sleep at night similarly showed no desaturation. The patient was monitored twice before treatment with a period of 1 week between monitoring. Each monitoring period exceeded $2 \mathrm{~h}$. Arterial blood gas was analysed eight times over a three-month period. A respiratory stimulant-carbonic anhydrase inhibitor; acetazolamide $\left(250 \mathrm{mg} \cdot\right.$ day-1$\left.^{-1}\right)$ was prescribed to prevent hypoxaemia with hypercapnia. Following the administration of acetazolamide, apnoeas were no more evident during wakefulness, and several breaths occurred between sighs in a trace of the patient's breathing (fig. 2c; the wakefulness of the patient was ascertained by the physicians through video monitoring). After treatment, oximeter monitoring during sleep at night showed no desaturation as similarly noted before treatment. The lowest $\mathrm{Sa}_{\mathrm{a}} \mathrm{O}_{2}$ at night was $94 \%$, and $99 \%$ of the night $\mathrm{Sa}_{\mathrm{a}} \mathrm{O}_{2}$ levels of the patient exceeded $96 \%$. Since the administration of acetazolamide, the patient has no longer been hypoxaemic on follow-up for $>1$ yr: $\mathrm{Pa}_{2} \mathrm{O}_{2} 14.3(0.9) \mathrm{kPa}, 95 \% \mathrm{CI}$ (13.615.0); $\mathrm{Pa}_{1} \mathrm{CO}_{2} 4.9$ (0.3) kPa, (4.7-5.1); pH 7.385 (0.02) (7.370-7.400); $n=9$. (fig. 1), although he continues to exhibit sighing while breathing during the obervation period. His dyspnoea has also slightly improved.

\section{Discussion}

In general, a patient who shows abnormal breathing with deterioration of the arterial blood gases during wakefulness is prone to show a further deterioration in blood gases during sleep. However, this patient showed abnormal breathing (sighs with apnoea) only during wakefulness. Before acetazolamide treatment, the patient's breathing mimicked Biot's respiration, which is most commonly seen with disease in the pons [6,7], although his breathings were not cluster breathings. When a patient presents with both abnormal breathing and abnormal arterial blood gas data, it is important to detect the underlying organic disease. However, we were unable to detect any organic abnormalities responsible for this patient's breathing and abnormal arterial blood gas data by conventional examination methods including MRI, CSF analysis, hypoxic and hypercapnic responses and pulmonary function tests. Given the absence of evidence for organic disease, the disorder seen in this patient was thought to involve a functional abnormality of the breathing pattern under cortical, or perhaps voluntary control. However, such abnormalities in breathing pattern attributed to cortical or psychological
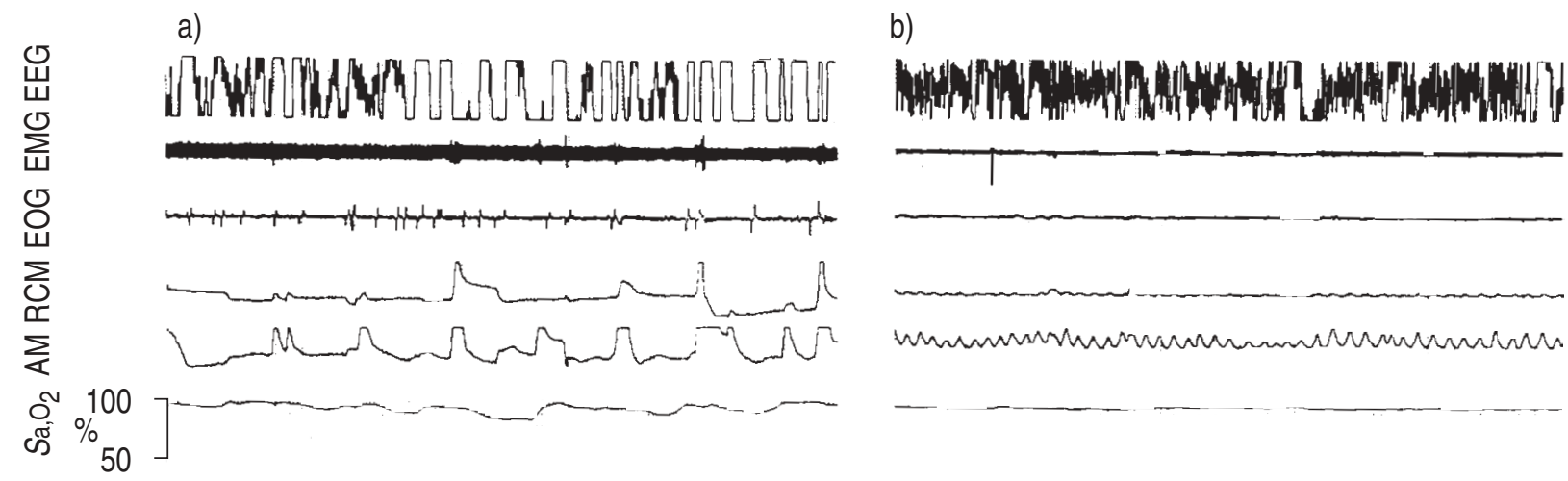

c)

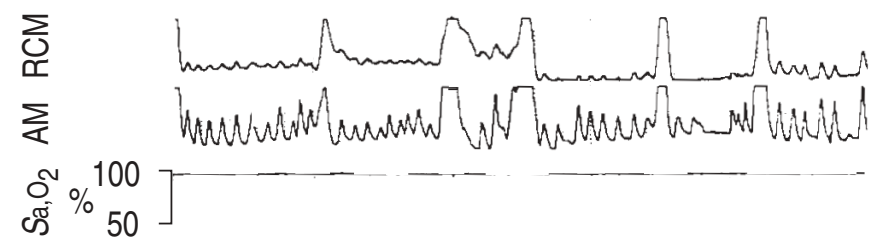

Fig. 2. - Continuous tracings of several parameters from the patient during a) wakefulness and b) sleep before acetazolamide treatment. c) tracings of several parameters during wakefulness after treatment are also shown. Tracings represent electroencephalogram (EEG), electromyogram (EMG) of the chin, electro-oculogram (EOG), ribcage ( $\mathrm{RCM}$ ) and abdominal (AM) motion from respiratory inductance plethysmography, and arterial $\mathrm{O}_{2}$ saturation $\left(\mathrm{S}_{\mathrm{a}}, \mathrm{O}_{2}\right)$. Inductance plethysmography and $\mathrm{S}_{\mathrm{a}, \mathrm{O}_{2}}$ were applied during wakefulness after treatment, and alertness was ascertained through video monitoring. 
causes are typically seen in patients with hyperventilation syndrome $[8,9]$. This patient, however, showed hypercapnia with apnoea while awake. Therefore, we described this patient as a case of awake apnoea without sleep apnoea, due to some unknown respiratory control abnormality.

Recently, it has been reported that neuromechanical inhibition of inspiratory muscle activity at high tidal volume, even when ventilation was executed by passive mechanical ventilation, exhibited a memory effect [10]. This memory effect was reflected in the prolongation of expiratory time, which persisted in the face of substantial increases in chemoreceptor stimuli. LeEvers et al [10] also reported that the end-tidal arterial carbon dioxide tension levels at the start of breathing following hyperventilation with high tidal volume were higher than the end-tidal carbon dioxide tension levels at the apnoea threshold. The patient's hypercapnia before treatment with acetazolamide may be partially explained by this mechanism. Chemical stimulation by acetazolamide might act to surpass the cortical control abnormality between sighs and permit several breaths between each sigh (fig. 2c).

\section{References}

1. Rhoads GG, Brody JS. Idiopathic alveolar hypoventilation: clinical spectrum. Ann Intern Med 1969; 71: 271278.
2. Mellins RB, Balfour HH Jr, Turino GM, Winters RW. Failure of automatic control of ventilation (Ondine's Curse). Medicine 1970; 49: 487-504.

3. Farmer WC, Glenn WW, Gee JB. Alveolar hypoventilation syndrome. Studies of ventilatory control in patients selected for diaphragm pacing. Am J Med 1978; 64: 39-49.

4. McNicholas WT, Carter J, Rutherford R, Zamel N, Phillipson EA. Beneficial effect of oxygen in primary alveolar hypoventilation with central sleep apnea. Am Rev Respir Dis 1982; 125: 773-775.

5. Chin K, Ohi M, Kita H, Otsuka N, Oku Y, Mishima M, Kuno K. Hypoxic ventilatory response and breathlessness following hypocapnic and isocapnic hyperventilation. Chest 1997; 112: 154-163.

6. Kryger MH. Abnormal control of breathing and sleep disorders. In: Kryger MH, ed. Introduction to Respiratory Medicine. 2nd ed. New York, Churchill Livingstone, 1990; pp. 109-131.

7. Plum F, Leigh J. Abnormalities of central mechanisms. In: Hombein TF, ed. Regulation of Breathing, part II. Lung Biology in Health and Disease Vol. 17. New York, Dekker, 1981; pp. 989-1067.

8. Brashear RE. Hyperventilation syndrome. Lung 1983; 161: 257-273.

9. Chin K, Hirai M, Kuriyama T, et al. Hypoxaemia in patients with hyperventilation syndrome. $Q$ J Med 1997; 90: 477-485.

10. Leevers AM, Simon PM, Xi L, Dempsey JA. Apnoea following normocapnic mechanical ventilation in awake mammals: a demonstration of control system inertia. $J$ Physiol (Lond) 1992; 472: 749-768. 